\title{
A Short Happy View of Our Emulation of Faculty
}

Having served as a successful scholar and teacher of college English, and also as a librarian, I would like to make some comparisons between the two professions. College teaching has all the precision of a coven of witches. No one knows precisely how to teach anyone anything. The simple fact is that we still haven't the slightest inkling of what goes on in the mind during the learning process; consequently, results are impossible to define. Nevertheless, each teacher tries his own thing, and some of it works somehow for some students. Most of the effort is wasted, as any successful teacher realizes.

This free-floating condition is the perfect refuge for opportunists who learn to play according to the rules of the guild that lead to rewards, and they have come into college teaching in droves during the past twenty years, the only period in history when this profession has paid a living wage. In the past three years, standards of classroom performance and of grading in colleges and universities have slipped alarmingly.

With the present shortage of jobs, the teaching profession has become obscenely competitive, with scholars grinding out articles like sausages from a casing machine, while their wives market them. The threat of nontenure, which means for the faculty termination of employment, hangs over the young like a sword of Damocles, and because of the high percentage of faculty already on tenure, denial of tenure to those coming up has become commonplace.

Is this the profession with which we want to compare ourselves? If so, I wonder why. Is this the kind of life that librarians want to lead? Or are we after a cushy version of it-all the benefits and none of the stress? No grinding demands for doctoral degrees? No pressures for publication? No termination if tenure is denied? It is possible to get the cushioned version in weak institutions, where no standards or pressures are applied to the teaching faculty. But who in the world would want to work in one? In colleges and universities where full faculty equivalency means competition on an even basis with high-powered academicians, most librarians stand only to lose. The Joint Statement on Faculty Status of College and University Librarians now under consideration for endorsement by ACRL, AAC, and AAUP states quite clearly: "They [librarians] must go through the same process of evaluation and meet the same standards as other faculty members." (CRL Neus, v. 33, no. 8 (Sept. 1972), p. 210. Emphasis added.) In any university of quality, this means no promotion above the rank of instructor without a Ph.D. degree.

In any healthy academic library under adequate leadership, the only faculty benefit denied librarians is the longer vacation period. In turn, li- 
brarians are free from the publish-or-perish and the tenure-or-sink syndromes. Within the past few years, the library-faculty of Cornell University, as well as at Hofstra University during my term there, voted down, by a margin of 2-1 in both cases, the option of moving to full faculty equivalency, on the basis that they had far more to lose than to gain. Others throughout the country have expressed disdain at being compared to faculty, rather than having their distinction as librarians fully recognized.

Why do we ignore the fact that the rich and complex knowledge, the highly professionalized and varied skills demanded by librarianship-the very elements that make this an exciting profession constantly stretching out ahead of the best of us over a long professional career-are the strongest bases on which to demand our share of the university's benefits to the fullest extent?

Two basic conditions are required. The library must be established at a high level in the eyes of its faculty, and it must recruit and hold a staff of librarians of academic worth. Both conditions depend on generating dynamics in the library that make it an exciting academic enterprise within the university structure. Both conditions can be attained without full faculty equivalency. And then, who in the world needs it?

ELLSWORTH Mason 